\title{
The association of the age, period, and birth cohort with 15-year changes in body mass index and waist circumference in adults: Tehran lipid and glucose study (TLGS)
}

Maryam Barzin', Shayan Aryannezhad ${ }^{1}$, Mohammad Bagheri ${ }^{1}$, Maryam Mahdavi ${ }^{1}$, Majid Valizadeh', Fereidoun Azizi ${ }^{2}$ and Farhad Hosseinpanah ${ }^{1 *}$

\begin{abstract}
Objective: To examine the association of age, period, and birth cohort with body mass index (BMI) and waist circumference (WC) changes among the participants of the Tehran Lipid and Glucose Study from 1999 to 2015.

Methods: This prospective cohort study included 4895 participants aged $\geq 20$ years (41.3\% men), who were divided into twelve gender stratified groups, having a ten-year age difference between them. Analyses were conducted to explicitly assess the association of age vs. period on BMI and WC changes. In addition, we evaluated BMI and WC changes among different birth cohorts.

Results: Upon 15 years of follow-up, the mean BMI of men and women increased from $26.0 \pm 3.9$ to $27.5 \pm 4.3 \mathrm{~kg} / \mathrm{m}^{2}$ and from $27.5 \pm 4.8$ to $29.9 \pm 5.4 \mathrm{~kg} / \mathrm{m}^{2}$ (P trend $<0.001$ ), and this trend was accompanied by an increase in WC from $88.8 \pm 10.9$ to $97.8 \pm 10.4 \mathrm{~cm}$ and from $87.3 \pm 12.4$ to $95.8 \pm 12.1 \mathrm{~cm}$, respectively $(P$ trend $<0.001)$. Men and women in all age cohorts tended to have a rise in their BMI and WC with aging throughout the follow-up period. For men, this trend was more prominent in younger birth cohorts at phase III for BMI and at phases III and V for WC (indicating a significant negative association with birth cohort). For women, this trend was more prominent in older birth cohorts at both phases III and V for BMI and WC (indicating a significant positive association with the birth cohort).

Conclusion: The rise in BMI and WC was strongly associated with age in both sexes. The men born in the recent birth cohorts and the women born in earlier birth cohorts had the most alarming BMI and WC trends. More efforts must be spent on obesity prevention policies, especially for younger men.
\end{abstract}

\section{Background}

Obesity is highly prevalent in developed and developing countries [1-3]. In the recent decades, Iran, as a developing country, has been experiencing an alarming rise in the prevalence of obesity; over an 8-year period, the overall prevalence of obesity in the country increased

\footnotetext{
*Correspondence: fhospanah@endocrine.ac.ir

${ }^{1}$ Obesity Research Center, Research Institute for Endocrine Sciences,

Shahid Beheshti University of Medical Sciences, Tehran, Iran

Full list of author information is available at the end of the article
}

from $13.6 \%$ in 1999 to $22.3 \%$ in 2007 (OR $=1.08$ per year) [4]. Increasing trends in general and abdominal obesity have been reported in both genders in Iran's capital, Tehran. This trend has contributed to an overall 36 and $34 \%$ increased risk of general and abdominal obesity from 1999 to 2011, respectively [5].

Various patterns in trends of obesity can be explainable by many sociodemographic, socioeconomic, and lifestyle factors. To explore these patterns, it is necessary to assess overtime changes in measures of general obesity

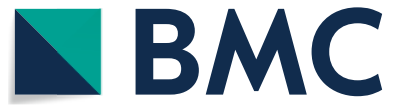

(c) The Author(s) 2022. Open Access This article is licensed under a Creative Commons Attribution 4.0 International License, which permits use, sharing, adaptation, distribution and reproduction in any medium or format, as long as you give appropriate credit to the original author(s) and the source, provide a link to the Creative Commons licence, and indicate if changes were made. The images or other third party material in this article are included in the article's Creative Commons licence, unless indicated otherwise in a credit line to the material. If material is not included in the article's Creative Commons licence and your intended use is not permitted by statutory regulation or exceeds the permitted use, you will need to obtain permission directly from the copyright holder. To view a copy of this licence, visit http://creativecommons.org/licenses/by/4.0/. The Creative Commons Public Domain Dedication waiver (http://creativeco mmons.org/publicdomain/zero/1.0/) applies to the data made available in this article, unless otherwise stated in a credit line to the data. 
(e.g., body mass index [BMI]) and abdominal obesity (e.g., waist circumference [WC]) in individuals (i.e., the age effect); and based on population-wide behavioral changes and other age-independent exposures (i.e., the period effect); as well as based on intra-individual differences in the people born in different times (i.e., the birthcohort effect) [6]. Rising trends in BMI and WC with aging, as observed in cross-sectional studies, could be the result of the age and birth-cohort effects. On the other hand, increases in BMI and WC with aging, as reported in longitudinal studies, might be due to period effects. The simultaneous assessment of the age, period, and birth-cohort effects on BMI and WC require longitudinal analyses with repeated measures in the same individuals [7-9].

Over the last few decades, Iran has experienced an epidemiological transition from a traditional to a western lifestyle [10]. There are no recent studies evaluating age and/or cohort effects on BMI and WC based on repeated measurements in Iran. Here, we investigated the association of age, period, and birth-cohort with BMI and WC changes in the framework of a prospective cohort study within a 15-year follow up period.

\section{Material and methods}

\section{Study population}

The Tehran Lipid and Glucose Study (TLGS) is a longitudinal cohort, which commenced in 1999 with the objective of determining the prevalence of non-communicable diseases among urban residents of Tehran, as a representative sample of the total population of Iran's capital. A multistage stratified cluster random sampling technique was used to select 15,010 people aged $\geq 3$ years old. From this population, only individuals above 20 years of age who participated in phase I (1999-2001), phase III (2006-2008), and phase V (2012-2015) of the study were enrolled. The intervals between each two assessments (from phase III to phase I and from phase V to phase III) were approximately six years. The details of the study have been published elsewhere [11]. After excluding the subjects aged $<20$ years $(n=4647)$, those with cancer $(n=44)$, pregnant participants $(n=80)$, the patients using glucocorticoids $(n=211)$, and the participants who lost the follow-up or had not participated in all the three phases $(n=5133)$, the data of 4895 subjects were used in this longitudinal study. These individuals included 2024 men $(41.3 \%)$ and 2871 women (58.7\%) who attended phases I, III, and V of TLGS with a median follow-up of 13.0 (IQ: 12.3-13.9) years. This study was approved by the Research Ethics Committee of the Research Institute for Endocrine Sciences, Shahid Beheshti University of Medical Sciences, and informed written consent was obtained from all subjects. All procedures were conducted in accordance with the principles of the Declaration of Helsinki.

\section{Measurements and definitions}

Weight and height were determined using a digital electronic weighing scale (Seca 707; range: $0.1-150 \mathrm{~kg}$, Hanover, MD, accuracy of up to $100 \mathrm{~g}$ ) and a tape meter stadiometer, respectively. Waist circumference was measured at the level of the umbilicus by a trained individual, and BMI was calculated as weight $(\mathrm{kg}) /$ height $\left(\mathrm{m}^{2}\right)$ [12]. Educational level was categorized into $\leq 12$-year education (primary school, secondary school, and high-school diploma) and $>12$ years of education (i.e., university level). Smoking status was categorized into yes/no, 'Yes' meaning tobacco smoking (cigarette, pipe, or water pipe) at the time of examination and 'no' as no smoking at the time (ex- or never-smokers). Information on leisure-time physical activity (LTPA) were collected using a Persiantranslated form of the Modifiable Activity Questionnaire (MAQ) [11], which was categorized into the light or nonactive (MET $<600 \mathrm{~min} /$ week) and moderate/vigorous or active (MET $\geq 600 \mathrm{~min} /$ week) groups [13]. Marital status was regarded as either married or unmarried (including never-married, widowed, and divorced).

\section{Statistical analysis}

Continuous variables were expressed as mean $\pm \mathrm{SD}$ and categorical variables as number (percent). These variables were compared between respondents and non-respondents using $t$-test for continuous variables and Chi square for categorical variables. A series of repeated measures models were used to assess differences in anthropometric factors between the three phases. Differences in categorical factors (i.e., smoking, physical activity, marital status, and education) along the follow-up period were analyzed using the generalized estimated equation (GEE) method with an autoregressive working correlation structure and a logistic model. Post-hoc Bonferroni correction was used for pairwise comparisons. Analyses were stratified by sex and age group. Mixed effects models with fixed and random individual-level effects and random slopes were used to assess differences in anthropometric factors among individuals over time. The stratified models included age and age-squared, as well as age interaction with year to determine how the survey year may vary by age. Figures were stratified by age groups to provide insights into the period-specific association of covariates. All analyses were performed in the SPSS statistical software package (SPSS for Windows; SPSS Inc., Chicago, IL, USA; Version 20.00), and mixed effects models were conducted using Stata's XTMIXED program. Statistical significance was considered two-tailed. 


\section{Results}

The mean age of study participants at baseline was $41.4 \pm 13.0$ years, and $58.7 \%$ of the participants were women. After 15 years of follow-up, mean BMI in men increased from $26.0 \pm 3.9$ to $27.5 \pm 4.3 \mathrm{~kg} / \mathrm{m}^{2}$ (P trend $<0.001$ ), and this trend was accompanied by an increase in mean WC from $88.8 \pm 10.9$ to $97.8 \pm 10.4 \mathrm{~cm}$ $\left(\mathrm{P}_{\text {trend }}<0.001\right)$. Women also showed elevations in mean BMI (from $27.5 \pm 4.8$ to $29.9 \pm 5.4 \mathrm{~kg} / \mathrm{m}^{2}$ ) and mean WC (from $87.3 \pm 12.4$ to $95.8 \pm 12.1 \mathrm{~cm}$ ) in this period (P trend $<0.001)$. More detailed characteristics of the study population across different phases of the study are available in Table 1. In comparison with those who completed the follow-up and entered the study (the respondent group, $n=4895)$, non-respondents $(n=5133)$ were older and had lower BMIs (supplementary Table 1).

Cohort-specific mean BMI and WC values in the study population are presented in Table 2. Rising trends in mean $\mathrm{BMI}$ and $\mathrm{WC}$ in each age cohort were observed for both genders (except for the BMI of $\geq 70$ years old in both genders and $\mathrm{WC}$ of $\geq 70$ years old women). Additionally, sex-specific mixed effects were estimated on BMI and WC changes in the studied population, adjusted for age, age squared, time, time*age, smoking, physical activity, education, and marital status (Tables 3 and 4). In Figs. 1 and 2, adjusted estimated means of BMI and WC in six age cohorts are shown according to the mean age of the group in each phase of the study, in men and women.

\section{Subgroup gender analysis}

Table 3 and Table 4 show sex-specific mixed effects models on BMI and WC of study participants, adjusted for confounding variables. Un-adjusted models also revealed the same statistical results, though the data is not shown. Coefficient with a $95 \%$ confidence interval $(95 \%$ CI) was calculated for various variables of the adjusted model. For the age variable, the coefficient $(95 \% \mathrm{CI})$ represents the changes in the BMI or WC contributed to a 1-year increase in age of participants throughout the study. For the time variable, the coefficient $(95 \% \mathrm{CI})$ represents the changes in the BMI or WC contributed to change in time (Phase V or III in reference to phase I). Time*age indicates the interaction of these two variables, representing the changes in the BMI or WC contributed to change in time, independent of changes in age. In brief, the adjusted models showed men in all age cohorts had a rise in BMI with aging throughout the follow-up period (coefficient for age: 0.28, 95\% CI: 0.20, 0.35). However, as shown in Fig. 1-A, this rise was more prominent in younger cohorts at phase III (coefficient for time*age: $-0.014,95 \%$ CI: $-0.027,-0.002)$, indicating a significant negative association with birth cohort. Considering WC changes, all age cohorts had a rising trend with aging throughout the follow-up (coefficient for age: 0.77, 95\% CI: $0.57,0.96)$. Significant negative association with birth cohort were observed at phases III and V (coefficient for time*age: $-0.06,95 \%$ CI: $-0.10,-0.03$ and -0.06 , 95\%

Table 1 Sex-specific characteristics of study population across phases I, III, and V

\begin{tabular}{|c|c|c|c|c|c|c|}
\hline & Phase I & Phase III & Phase V & $P_{1-111}^{a}$ & $P_{\text {III-V }}$ & $P_{1-V}$ \\
\hline \multicolumn{7}{|l|}{$\operatorname{Men}(N=2024)$} \\
\hline Weight $(\mathrm{kg})$ & $75.2 \pm 12.3$ & $78.9 \pm 13.2$ & $80.5 \pm 14.3$ & $<0.001$ & $<0.001$ & $<0.001$ \\
\hline WC (cm) & $88.8 \pm 10.9$ & $96.4 \pm 10.1$ & $97.8 \pm 10.4$ & $<0.001$ & $<0.001$ & $<0.001$ \\
\hline BMI $\left(\mathrm{kg} / \mathrm{m}^{2}\right)$ & $26.0 \pm 3.9$ & $27.2 \pm 4.0$ & $27.5 \pm 4.3$ & $<0.001$ & $<0.001$ & $<0.001$ \\
\hline Smoking (non-smokers) & $1516(75.4)$ & $1549(77.8)$ & $1609(79.7)$ & 0.006 & 0.011 & $<0.001$ \\
\hline Physical activity (active) ${ }^{b}$ & $408(20.3)$ & $228(19.6)$ & $208(19.4)$ & 0.431 & $>0.999$ & $>0.999$ \\
\hline Marital status (married) & $1698(83.9)$ & $1903(94.2)$ & 1966 (97.2) & $<0.001$ & $<0.001$ & $<0.001$ \\
\hline Education (> 12years) & $374(18.5)$ & $488(24.5)$ & $545(26.9)$ & $<0.001$ & $<0.001$ & $<0.001$ \\
\hline \multicolumn{7}{|l|}{ Women $(N=2871)$} \\
\hline Weight $(\mathrm{kg})$ & $67.6 \pm 12.0$ & $70.2 \pm 12.1$ & $71.7 \pm 12.6$ & $<0.001$ & $<0.001$ & $<0.001$ \\
\hline $\mathbf{W C}(\mathrm{cm})$ & $87.3 \pm 12.4$ & $90.8 \pm 12.6$ & $95.8 \pm 12.1$ & $<0.001$ & $<0.001$ & $<0.001$ \\
\hline BMI $\left(\mathrm{kg} / \mathrm{m}^{2}\right)$ & $27.5 \pm 4.8$ & $28.9 \pm 4.9$ & $29.9 \pm 5.4$ & $<0.001$ & $<0.001$ & $<0.001$ \\
\hline Smoking (non-smokers) & $2783(97.6)$ & $2731(97.3)$ & $2771(96.9)$ & 0.978 & 0.348 & 0.058 \\
\hline Physical activity (active) ${ }^{b}$ & $760(26.7)$ & $240(13.8)$ & $166(12.9)$ & $<0.001$ & $>0.999$ & $<0.001$ \\
\hline Marital status (married) & $2597(90.5)$ & $2732(95.2)$ & $2758(96.2)$ & $<0.001$ & $<0.001$ & $<0.001$ \\
\hline Education (> 12years) & $251(8.8)$ & $377(13.4)$ & $449(15.7)$ & $<0.001$ & $<0.001$ & $<0.001$ \\
\hline
\end{tabular}

Data are presented as mean \pm SD or $\mathrm{n}(\%)$

WC waist circumference; $B M I$ body mass index

${ }^{\text {a }}$ Adjustment for multiple comparisons with Bonferroni correction (comparisons with phase 1 and phase3)

${ }^{b}$ Active Physical activity was defined as MET $\geq 600 \mathrm{~min} /$ week by using the Modifiable Activity Questionnaire 
Table 2 Sex-specific body mass index (BMI) and waist circumference of different age cohorts of study population across phases I, III, and $\mathrm{V}$

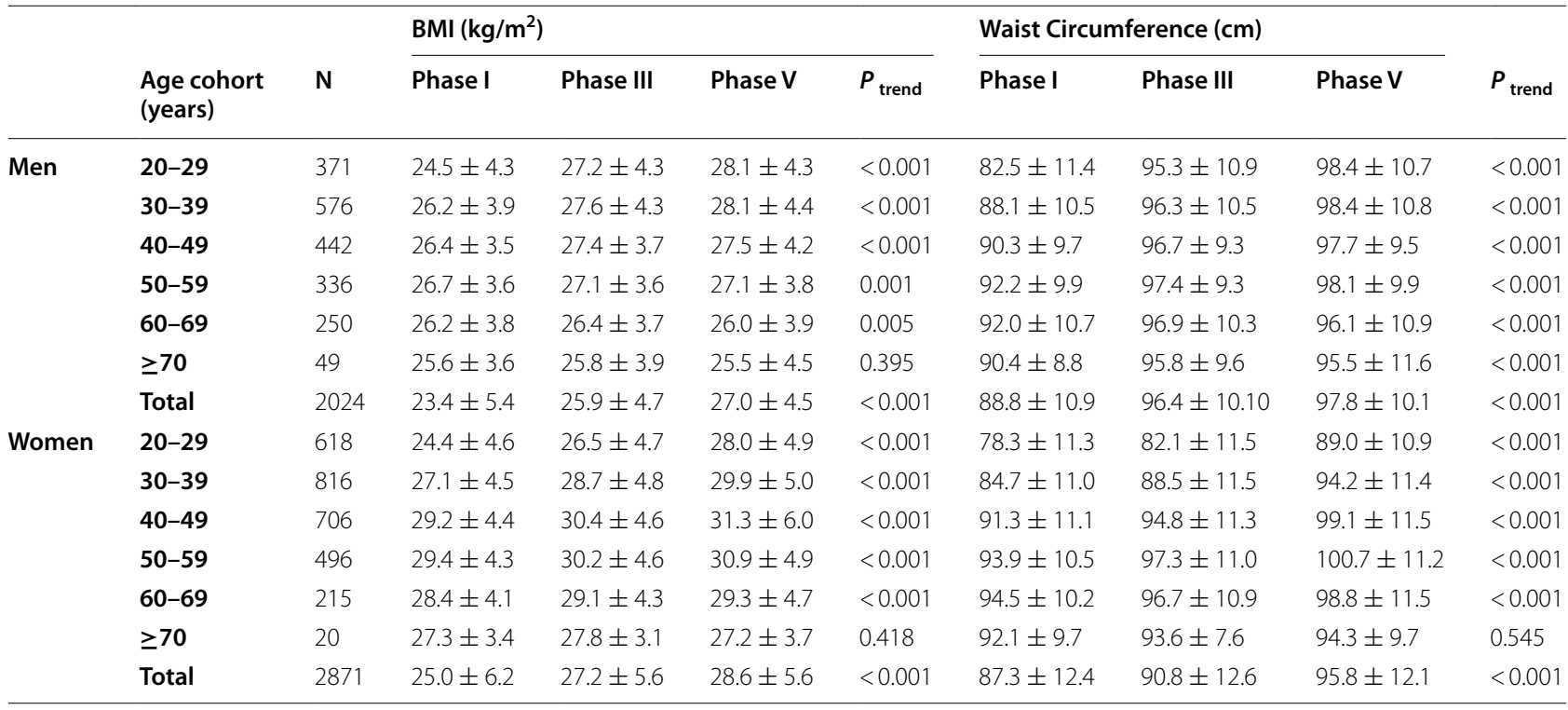

Data are presented as mean \pm SD

CI: $-0.12,-0.001$, respectively) (Fig. 2-A). Moreover, it was observed that higher physical activity, smoking, lower education, and not being married were associated with lower weight and WC.

Women in all age cohorts showed a rise in BMI throughout the follow-up with aging (coefficient for age: 0.61, 95\% CI: 0.53,0.69). However, this trend was influenced by a positive association with birth cohort at both phases III and V (coefficient for time*age 0.04, 95\% CI: 0.03, 0.05 and $0.8,95 \%$ CI: 0.06, 0.11, respectively), meaning that older age cohorts were more likely to gain weight with time (Fig. 2-A). Regarding WC changes, all age cohorts displayed a rising trend throughout the follow-up period with aging (coefficient for age: 1.32, 95\% CI: 1.14, 1.50). In line with BMI changes, this trend was influenced by a positive association with birth cohort at both phases III and V (coefficient for time"age 0.13, 95\% CI: 0.09, 0.16 and 0.13, 95\% CI: 0.07, 0.19, respectively) (Fig. 2-B). Regarding the association of other variables, higher physical activity, smoking, a higher education, and not being married were associated with lower weight and WC.

\section{Discussion}

In this 15-year population-based longitudinal study, gender-specific changes of BMI and WC in the adult population of Tehran were evaluated. The rises in BMI and WC were strongly associated with aging throughout the follow up period. Increases in BMI and WC were more prominent in younger birth cohorts in men, and older birth cohorts in women.
A large body of evidence suggests that weight, BMI, and WC increase throughout most of adult life [14-17], which is in line with our findings regarding the positive association of aging with obesity measures, observed in both genders. A prospective longitudinal study in Norway recently showed that mean weight in middle-aged men and women (aged 26-54years) increased significantly during a 10-year follow-up while it reduced in elderly men and women (aged 60-69years); however, mean WC increased throughout the follow up in all age groups [18]. The recent findings were completely in accordance with those of the present study. We observed an overall positive association of aging with BMI in both genders which in combination with the observed inverse association of BMI with age squared suggested an inverted U-shaped relationship between age and weight gain. This implies that the rapid weight gain seen in young and middle-aged men and women will most likely be reversed in the elderly. The weight reduction with aging reported in the elderly could be a result of decreased appetite and calorie intake, as well as substantial loss of muscle mass due to the aging process [19]. Apart from age-related muscle loss, disease-related muscle loss could also explain this phenomenon, as many chronic diseases (with particularly higher prevalence in older individuals) could also accelerate decrease of muscle mass, such as diabetes, hypogonadism in men, growth hormone deficiency, hyperthyroidism, and hypercortisolism [20]. However, in older men and women, despite a drop in BMI, WC increased over years, which could be a 
Table 3 Sex-specific mixed effects estimates on body mass index (BMI) of study population, coefficient $(95 \% \mathrm{Cl})$

\begin{tabular}{|c|c|c|}
\hline & Coefficient $(95 \% \mathrm{Cl})$ & $P$-value \\
\hline \multicolumn{3}{|l|}{ Men } \\
\hline Age & $0.28(0.20,0.35)$ & $<0.001$ \\
\hline $\mathrm{Age}^{2}$ & $-0.003(-0.004,-0.002)$ & $<0.001$ \\
\hline \multicolumn{3}{|l|}{ Time (Ref: Phase I) } \\
\hline Phase III & $1.68(1.06,2.30)$ & $<0.001$ \\
\hline Phase V & $1.60(0.41,2.78)$ & 0.008 \\
\hline \multicolumn{3}{|l|}{ Time*age (Ref: Phase I) } \\
\hline Phase III *age & $-0.014(-0.027,-0.002)$ & 0.028 \\
\hline Phase $V^{*}$ age & $-0.005(-0.028,0.018)$ & 0.662 \\
\hline Smoking (Ref: non-smoker) & $-0.38(-0.57,-0.19)$ & $<0.001$ \\
\hline Physical activity (Ref: high) & $0.16(0.05,0.27)$ & 0.005 \\
\hline Education (Ref: > 12 year) & $-0.07(-0.31,0.16)$ & 0.534 \\
\hline Spouse: (Ref: married) & $-1.03(-1.30,-0.77)$ & $<0.001$ \\
\hline \multicolumn{3}{|l|}{ Women } \\
\hline Age & $0.61(0.53,0.69)$ & $<0.001$ \\
\hline $\mathrm{Age}^{2}$ & $-0.006(-0.007,-0.005)$ & $<0.001$ \\
\hline \multicolumn{3}{|l|}{ Time (Ref: Phase I) } \\
\hline Phase III & $-1.24(-1.89,-0.59)$ & $<0.001$ \\
\hline Phase V & $-2.92(-4.20,-1.65)$ & $<0.001$ \\
\hline \multicolumn{3}{|l|}{ Time*age (Ref: Phase I) } \\
\hline Phase III *age & $0.04(0.03,0.05)$ & $<0.001$ \\
\hline Phase $V^{*}$ age & $0.08(0.06,0.11)$ & $<0.001$ \\
\hline Smoking (Ref: non-smoker) & $-0.69(-1.14,-0.23)$ & 0.003 \\
\hline Physical activity (Ref: high) & $0.12(0.02,0.23)$ & 0.024 \\
\hline Education (Ref: > 12year) & $0.74(0.46,1.03)$ & $<0.001$ \\
\hline Marital status: (Ref: married) & $-1.69(-2.03,-1.35)$ & $<0.001$ \\
\hline
\end{tabular}

Model includes age, age-squared, study phase year, age interacted with study phase year, smoking, education, and marital status

result of body composition changes. Age has been shown to affect body composition with older people having higher proportions of the adipose tissue to the lean mass [21]. Furthermore, age affects the distribution of the adipose tissue, with more intra-abdominal and visceral adipose tissues vs. peripheral subcutaneous fat mass being observed in the elderly [22]. Besides, spinal degenerative changes and a consequent reduction in height during the aging process could explain the increase of WC despite decreased or sustained weight in this age group [23].

In this study, a significant negative association of birth cohort with BMI and WC was observed in adult men, indicating notable general and central weight gain in the youngest compared with older birth cohorts. This finding was consistent with the observations of previous studies [7, 9, 24-30]. Iran, as a country located in the Middle East and North Africa region, is subjected to a dramatic epidemiological transition from a traditional to modern nutrition and lifestyle [10]. This modernization and associated lifestyle changes by encouraging sedentary habits and
Table 4 Sex-specific mixed effects estimates on waist circumference of study population, coefficient $(95 \% \mathrm{Cl})$

\begin{tabular}{|c|c|c|}
\hline & Coefficient $(95 \% \mathrm{Cl})$ & $P$-value \\
\hline \multicolumn{3}{|l|}{ Men } \\
\hline Age & $0.77(0.57,0.96)$ & $<0.001$ \\
\hline $\mathrm{Age}^{2}$ & $-0.006(-0.008,-0.004)$ & $<0.001$ \\
\hline \multicolumn{3}{|l|}{ Time (Ref: Phase I) } \\
\hline Phase III & $9.49(7.88,11.10)$ & $<0.001$ \\
\hline Phase V & $10.44(7.39,13.49)$ & $<0.001$ \\
\hline \multicolumn{3}{|l|}{ Time*age (Ref: Phase I) } \\
\hline Phase III*age & $-0.06(-0.10,-0.03)$ & $<0.001$ \\
\hline Phase $V^{*}$ age & $-0.06(-0.12,-0.001)$ & 0.045 \\
\hline Smoking (Ref: non-smoker) & $-1.12(-1.63,-0.61)$ & $<0.001$ \\
\hline Physical activity (Ref: high) & $0.77(0.48,1.07)$ & $<0.001$ \\
\hline Education (Ref: > 12year) & $-0.33(-0.95,0.29)$ & 0.295 \\
\hline Spouse: (Ref: married) & $-3.11(-3.83,-2.40)$ & $<0.001$ \\
\hline \multicolumn{3}{|l|}{ Women } \\
\hline Age & $1.32(1.14,1.50)$ & $<0.001$ \\
\hline $\mathrm{Age}^{2}$ & $-0.010(-0.013,-0.008)$ & $<0.001$ \\
\hline \multicolumn{3}{|l|}{ Time (Ref: Phase I) } \\
\hline Phase III & $-4.87(-6.57,-3.17)$ & $<0.001$ \\
\hline Phase V & $-2.84(-5.90,0.23)$ & 0.070 \\
\hline \multicolumn{3}{|l|}{ Time*age (Ref: Phase I) } \\
\hline Phase III*age & $0.13(0.09,0.16)$ & $<0.001$ \\
\hline Phase $V^{*}$ age & $0.13(0.07,0.19)$ & $<0.001$ \\
\hline Smoking (Ref: non-smoker) & $-0.76(-2.12,0.60)$ & 0.274 \\
\hline Physical activity (Ref: high) & $0.80(0.46,1.15)$ & $<0.001$ \\
\hline Education (Ref: > 12year) & $2.63(1.83,3.42)$ & $<0.001$ \\
\hline Spouse: (Ref: married) & $-5.25(-6.26,-4.24)$ & $<0.001$ \\
\hline
\end{tabular}

Model includes age, age-squared, study phase year, age interacted with study phase year, smoking, education, and marital status

excess calorie intake have increased the risk of obesity and overweight in the new generations of Iranians, and as a consequence, the prevalence of obesity among children and adolescents has increased [31-33]. Overweight or obese children and adolescents are likely to remain so in adulthood, and this may explain why people who were born in the most recent birth cohorts were more susceptible to BMI and WC elevations than older individuals born in the years of economic and social instability. Moreover, in older men, this negative association of birth cohort could be partially explained by reduced calorie intake and aging-associated loss of appetite [19]. In addition, exposure to stress might lead to unhealthy behaviors which could contribute to weight gain as well [34]. Another explanation for the observed association of weight gain with younger birth cohorts could be more job commitments of younger generations and their less time for physical exercises and self-care, delivering them more prone to obesity. In contrast, the individuals born in earlier birth cohorts spent their youth in more active 

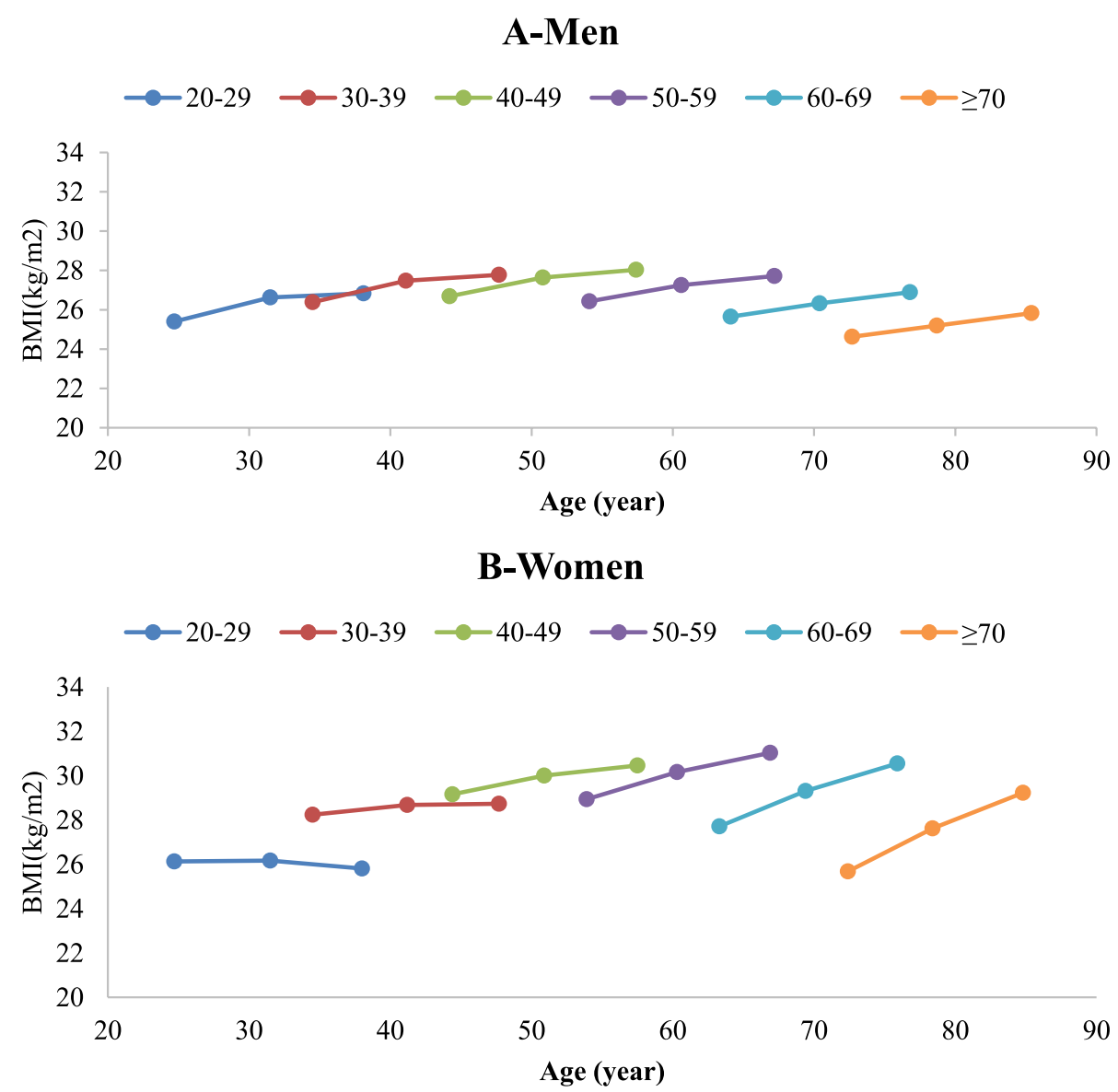

Fig. 1 Trends of body mass index (BMI) in different age cohorts of study population across phases I, III, and V; in men (A) and women (B)

lifestyles and were less exposed to cumulative obesogenic health behaviors [35, 36]. Another explanation for the negative impact of birth cohort on men could be related to the survival bias which might be a consequence of premature mortality among older obese individuals [37]. In contrast to our findings, a study on Chinese adults found that being overweight was more common among middle-aged men born between 1950 and 1975 and revealed that the prevalence of overweight among Chinese adults decreased rapidly in the most recent birth cohorts (i.e., after 1975) [38]. The observed difference between the two studies may be due to economic and social differences between the two populations. China has become one of the world's fastest growing economies since the 1980s and with increased access to health information and the implantation of new health policies, has somehow managed to overcome the epidemiological transition [39].

In women, however, we observed a positive association of birth cohort with BMI. Regarding the difference between men and women in this area, both biological and social factors may be accountable for justifying the reported disparity between the two genders. The younger women born in recent birth cohorts are more likely to have higher education, have fewer pregnancies, and adhere to feminine beauty standards paying a premium for slimness as a desirable body form [40]. Moreover, menopausal changes affect women in their later years, making elderly women more prone to obesity [41, 42]. Another factor contributing to the observed gender disparity may be a higher health awareness level among young women rather than men [43].

We are aware that our research may have some limitations. First, since our subjects were only urban residents in Tehran, our findings cannot be extrapolated to the entire country's population. Second, in order to reach solid conclusions about the association of the "time period" with BMI and WC, more measurements and longer follow-up periods are needed. Third, the body composition of the participants was not recorded in our study; therefore, we could not speculate to what degree the reported weight fluctuations might correspond to body fat percentage changes. Moreover, we did 

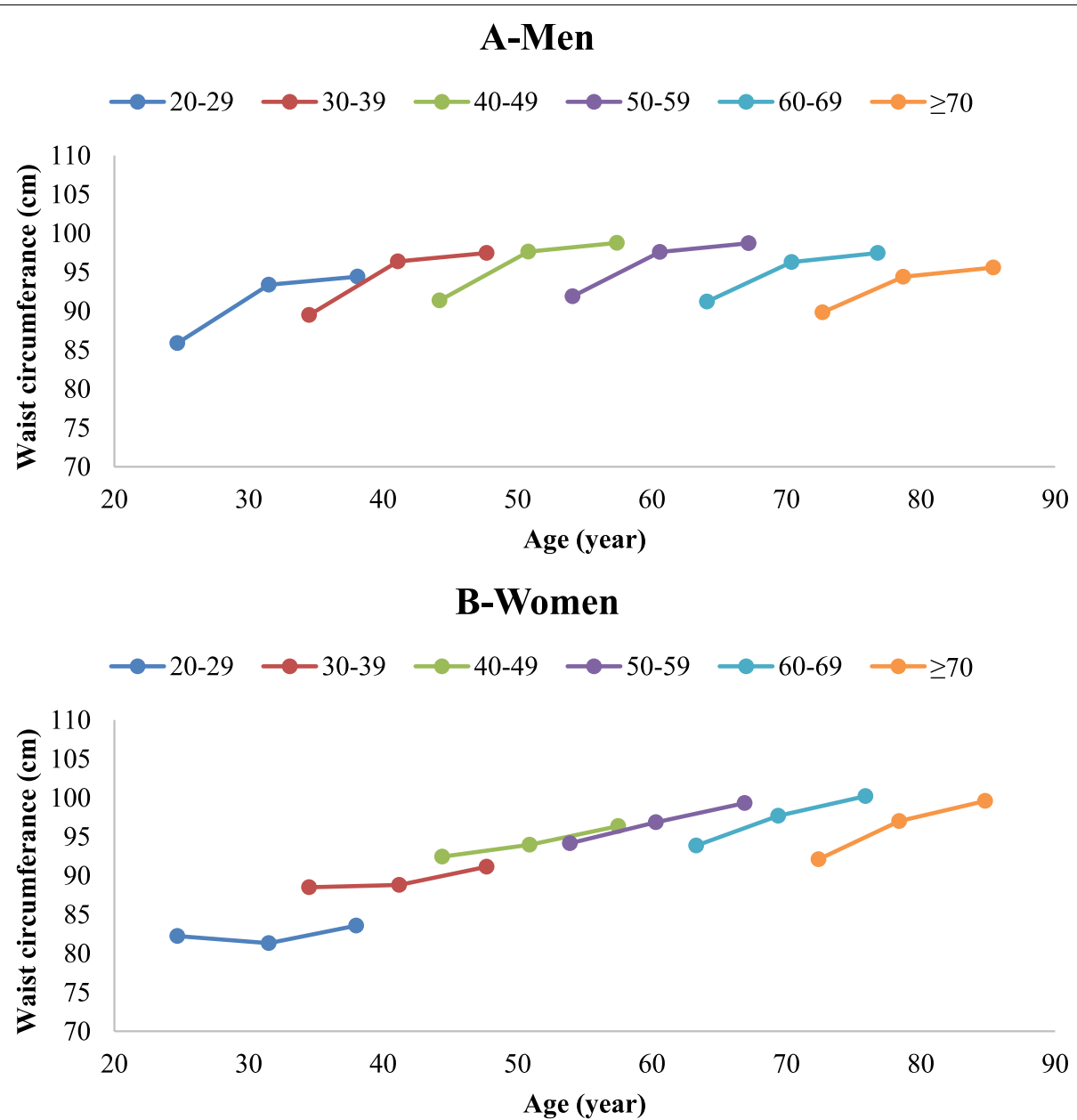

Fig. 2 Trends of waist circumference in different age cohorts of study population across phases I, III, and V; in men (A) and women (B)

not consider the role of the participants' dietary intake and nutritional habits on their BMI and WC. However, the current study has several strengths worth mentioning. Anthropometric measurements were performed by trained staff instead of relying on self-reports, increasing the accuracy of measurements. Moreover, our research included participants from a wide adult age spectrum and birth cohorts, who were tracked for 15 years and underwent three measurement intervals.

In conclusion, this study demonstrated rising agedependent trends in the BMI and WC of Tehranian adult men and women. However, there were substantial gender-specific associations with birth cohorts, indicating that the men born in recent birth cohorts and the women born in earlier birth cohorts had the most alarming trends in BMI and WC. Given Iran's epidemiological transition state, it seems that the nation has a heterogeneous tendency for weight gain, and our findings suggest that effective population-based obesity preventive measures should be targeted towards gender, age, and birth cohort, as the most potent determinants of obesity.

\section{Supplementary Information}

The online version contains supplementary material available at https://doi. org/10.1186/s12889-022-12810-z.

\section{Additional file 1.}

\section{Acknowledgments}

We express our appreciation to the participants of the study for their enthusiastic support and to the staff of the involved TLGS unite for their valuable help.

\section{Authors' contributions}

Maryam Barzin, Mohammad Bagheri and S.A. designed the study and prepared the manuscript and approved the final manuscript as submitted. M.M. analyzed and interpreted the data. M.V. and F.A. supervised the project, drafted the initial manuscript, and approved the final manuscript as submitted. F.H. conceptualized and designed the study, interpreted the data and critically revised the manuscript and approved the final manuscript as submitted. All authors reviewed the manuscript. The author(s) read and approved the final manuscript. 


\section{Funding \\ None.}

\section{Availability of data and materials}

The datasets used and analyzed during the current study are available from the corresponding author on reasonable request.

\section{Declarations}

\section{Ethics approval and consent to participate}

Informed consent was obtained from all participants. All methods were performed in accordance with the relevant guidelines and regulations (Declaration of Helsinki). This study was approved by the Ethics Committee of the Institute of Endocrinology and Metabolism of Shahid Beheshti University of Medical Sciences.

\section{Consent for publication}

Not Applicable.

\section{Competing interests}

The authors declare that they have no financial or non-financial competing interests.

\section{Author details}

'Obesity Research Center, Research Institute for Endocrine Sciences, Shahid Beheshti University of Medical Sciences, Tehran, Iran. ${ }^{2}$ Endocrine Research Center, Research Institute for Endocrine Sciences, Shahid Beheshti University of Medical Sciences, Tehran, Iran.

Received: 1 August 2021 Accepted: 21 February 2022

Published online: 02 March 2022

\section{References}

1. Finucane MM, Stevens GA, Cowan MJ, Danaei G, Lin JK, Paciorek CJ, et al. National, regional, and global trends in body-mass index since 1980: systematic analysis of health examination surveys and epidemiological studies with 960 country-years and 9.1 million participants. Lancet. 2011;377(9765):557-67.

2. Ogden CL, Carroll MD, Lawman HG, Fryar CD, Kruszon-Moran D, Kit BK, et al. Trends in obesity prevalence among children and adolescents in the United States, 1988-1994 through 2013-2014. Jama. 2016:315(21):2292-9.

3. Barzin M, Valizadeh M, Serahati S, Mahdavi M, Azizi F, Hosseinpanah F. Overweight and obesity: findings from 20 years of the Tehran lipid and glucose study. Int J Endocrinol Metab. 2018;16(4 Suppl):e84778.

4. Esteghamati A, Khalilzadeh O, Mohammad K, Meysamie A, Rashidi A, Kamgar M, et al. Secular trends of obesity in Iran between 1999 and 2007: National Surveys of risk factors of non-communicable diseases. Metab Syndr Relat Disord. 2010;8(3):209-13.

5. Barzin M, Keihani S, Hosseinpanah F, Serahati S, Ghareh S, Azizi F. Rising trends of obesity and abdominal obesity in 10 years of follow-up among Tehranian adults: Tehran lipid and glucose study (TLGS). Public Health Nutr. 2015:18(16):2981-9.

6. Diaz MDP, Icaza G, Nuñez L, Pou SA. Gastric Cancer Mortality Trends in the Southern Cone: Disentangling age, period and cohort patterns in Argentina and Chile. 2020;10(1):1526.

7. Juhaeri S. J, Jones DW, Arnett D. associations of aging and birth cohort with body mass index in a biethnic cohort. Obes Res. 2003;11(3):426-33.

8. Barone BB, Clark JM, Wang NY, Meoni LA, Klag MJ, Brancati FL. Lifetime weight patterns in male physicians: the effects of cohort and selective survival. Obesity (Silver Spring, Md). 2006;14(5):902-8.

9. Nooyens AC, Visscher TL, Verschuren WM, Schuit AJ, Boshuizen HC, van Mechelen W, et al. Age, period and cohort effects on body weight and body mass index in adults: the Doetinchem cohort study. Public Health Nutr. 2009;12(6):862-70.

10. Azizi F, Hadaegh F, Hosseinpanah F, Mirmiran P, Amouzegar A, Abdi $\mathrm{H}$, et al. Metabolic health in the Middle East and North Africa. Lancet Diabetes Endocrinol. 2019;7(11):866-79.
11. Azizi F, Ghanbarian A, Momenan AA, Hadaegh F, Mirmiran P, Hedayati $M$, et al. Prevention of non-communicable disease in a population in nutrition transition: Tehran lipid and glucose study phase II. Trials. 2009; 10(1):5.

12. NIH conference. Gastrointestinal surgery for severe obesity. Consensus development conference panel. Ann Intern Med. 1991;115(12):956-61.

13. Committee IR. Guidelines for data processing and analysis of the International Physical Activity Questionnaire (IPAQ)-short and long forms. http://www.ipaqkise/scoring.pdf. 2005

14. Tanamas SK, Shaw JE, Backholer K, Magliano DJ, Peeters A. Twelve-year weight change, waist circumference change and incident obesity: the Australian diabetes, obesity and lifestyle study. Obesity (Silver Spring). 2014;22(6):1538-45.

15. El Reda D, Ström P, Sandin S, Oh JK, Adami HO, Löf M, et al. Determinants of long-term weight change among middle-aged Swedish women. Obesity (Silver Spring). 2017;25(2):476-85.

16. Haftenberger M, Mensink GB, Herzog B, Kluttig A, Greiser KH, Merz B, et al. Changes in body weight and obesity status in German adults: results of seven population-based prospective studies. Eur J Clin Nutr. 2016;70(3):300-5.

17. Peter RS, Fromm E, Klenk J, Concin H, Nagel G. Change in height, weight, and body mass index: Iongitudinal data from Austria. Am J Hum Biol. 2014;26(5):690-6.

18. Jacobsen BK, Melhus M, Kvaløy K, Siri SRA, Michalsen VL, Broderstad AR. A descriptive study of ten-year longitudinal changes in weight and waist circumference in the multi-ethnic rural Northern Norway. The SAMINOR Study, 2003-2014. PLoS One. 2020;15(2):e0229234.

19. Pilgrim AL, Robinson SM, Sayer AA, Roberts HC. An overview of appetite decline in older people. Nurs Older People. 2015;27(5):29-35.

20. Kalyani RR, Corriere M, Ferrucci L. Age-related and disease-related muscle loss: the effect of diabetes, obesity, and other diseases. The lancet Diabetes \& endocrinology. 2014;2(10):819-29.

21. Beaufrère $B$, Morio $B$. Fat and protein redistribution with aging: metabolic considerations. Eur J Clin Nutr. 2000;54(Suppl 3):S48-53.

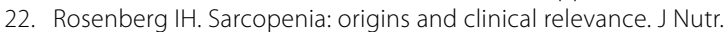
1997;127(5 Suppl):990s-1s.

23. Macek P, Terek-Derszniak M. Assessment of Age-Induced Changes in Body Fat Percentage and BMI Aided by Bayesian Modelling: A CrossSectional Cohort Study in Middle-Aged and Older Adults, vol. 15; 2020. p. 2301-11.

24. Jacobsen BK, Aars NA. Changes in body mass index and the prevalence of obesity during 1994-2008: repeated cross-sectional surveys and longitudinal analyses. The Tromsø StudyBMJ Open 2015;5(6):e007859.

25. Lund Haheim L, Lund Larsen PG, Sogaard AJ, Holme I. Risk factors associated with body mass index increase in men at 28 years follow-up. Qjm. 2006:99(10):665-71.

26. Drøyvold WB, Nilsen Tl, Krüger O, Holmen TL, Krokstad S, Midthjell K, et al. Change in height, weight and body mass index: longitudinal data from the HUNT study in Norway. Int J Obes. 2006;30(6):935-9.

27. Caman OK, Calling S, Midlöv P, Sundquist J, Sundquist K, Johansson S-E. Longitudinal age-and cohort trends in body mass index in Sweden - a 24-year follow-up study. BMC Public Health. 2013;13(1):893.

28. Reas DL, Nygård JF, Svensson E, Sørensen T, Sandanger I. Changes in body mass index by age, gender, and socio-economic status among a cohort of Norwegian men and women (1990-2001). BMC Public Health. 2007;7:269.

29. Pajunen P, Vartiainen E, Männistö S, Jousilahti P, Laatikainen T, Peltonen M. Intra-individual changes in body weight in population-based cohorts during four decades: the Finnish FINRISK study. Eur J Pub Health. 2012;22(1):107-12

30. Jacobsen BK, Aars NA. Changes in waist circumference and the prevalence of abdominal obesity during 1994-2008 - cross-sectional and longitudinal results from two surveys: the Troms $\varnothing$ study. BMC Obes. 2016:3:41.

31. Seaman DR. Weight gain as a consequence of living a modern lifestyle: a discussion of barriers to effective weight control and how to overcome them. J Chiropractic Human. 2013;20(1):27-35.

32. Popkin BM, Adair LS, Ng SW. Global nutrition transition and the pandemic of obesity in developing countries. Nutr Rev. 2012;70(1):3-21.

33. Hosseinpanah F, Serahati S, Barzin M, Aryannezhad S, Rezaie M, Valizadeh $M$, et al. Trends of Obesity in 10-Years of Follow-up among Tehranian 
Children and Adolescents: Tehran Lipid and Glucose Study (TLGS). Iran J Public Health. 2019;48(9):1714-22.

34. Kouvonen A, Kivimäki M, Väänänen $A$, Heponiemi T, Elovainio M, AlaMursula $L$, et al. Job strain and adverse health behaviors: the Finnish public sector study. J Occup Environ Med. 2007:49(1):68-74.

35. Dugan AG, Barnes-Farrell JL. Working mothers' second shift, personal resources, and self-care. Community Work Fam. 2020;23(1):62-79.

36. Garza JL, Dugan AG, Faghri PD, Gorin AA, Huedo-Medina TB, Kenny AM, et al. Demographic, health-related, and work-related factors associated with body mass index and body fat percentage among workers at six Connecticut manufacturing companies across different age groups: a cohort study. BMC Obes. 2015;2:43.

37. Mehta NK, Chang VW. Mortality attributable to obesity among middleaged adults in the United States. Demography. 2009;46(4):851-72.

38. Yang Y, Kelifa MO, Yu B, Herbert C, Wang Y, Jiang J. Gender-specific temporal trends in overweight prevalence among Chinese adults: a hierarchical age-period-cohort analysis from 2008 to 2015. Global Health Res Pol. 2020;5:42.

39. Cook IG, Dummer TJB. Changing health in China: re-evaluating the epidemiological transition model. Health policy (Amsterdam, Netherlands). 2004;67(3):329-43.

40. Tu Y-K, Chien K-L, Burley V, Gilthorpe MS. Unravelling the effects of age, period and cohort on metabolic syndrome components in a Taiwanese population using partial least squares regression. BMC Med Res Methodol. 2011;11(1):82.

41. Brown KA, lyengar NM, Zhou XK, Gucalp A, Subbaramaiah K, Wang H, et al. Menopause is a determinant of breast aromatase expression and its associations with BMl, inflammation, and systemic markers. J Clin Endocrinology Metab. 2017;102(5):1692-701.

42. Gravena AAF, Brischiliari SCR, Lopes TCR, Agnolo CMD, Carvalho MDB, Pelloso SM. Excess weight and abdominal obesity in postmenopausal Brazilian women: a population-based study. BMC Womens Health. 2013;13(1):46.

43. Bidmon S, Terlutter R. Gender Differences in Searching for Health Information on the Internet and the Virtual Patient-Physician Relationship in Germany: Exploratory Results on How Men and Women Differ and Why. J Med Internet Res. 2015;17(6):e156.

\section{Publisher's Note}

Springer Nature remains neutral with regard to jurisdictional claims in published maps and institutional affiliations.

Ready to submit your research? Choose BMC and benefit from:

- fast, convenient online submission

- thorough peer review by experienced researchers in your field

- rapid publication on acceptance

- support for research data, including large and complex data types

- gold Open Access which fosters wider collaboration and increased citations

- maximum visibility for your research: over 100M website views per year

At BMC, research is always in progress.

Learn more biomedcentral.com/submissions 